\title{
Abrigar/desabrigar: conhecendo o papel das famílias nesse processo ${ }^{1}$
}

\section{Providing shelter/depriving shelter: finding out about the role of families in this process}

\author{
Ana Mafalda Guedes Cabral Courinha Vassalo AZÔR² \\ Celia VECTORE²
}

\begin{abstract}
Resumo
A pesquisa objetivou conhecer o papel desempenhado pelas famílias de adolescentes ex-abrigados em uma instituição do município de Uberaba (MG), durante o processo de institucionalização/desinstitucionalização que viveram. Participaram do estudo cinco famílias que haviam recuperado a guarda dos filhos. Os materiais utilizados para coleta dos dados foram entrevistas semi-estruturadas com o pai ou a mãe dos adolescentes, com os próprios adolescentes e com a diretora do abrigo; fichas de identificação socioeconômica; verificação de livros de registros do abrigo e das pastas arquivadas com informações dosadolescentes; e diários de campo da pesquisa. Os resultados apontaram que as causas que levam ao abrigo são multifatoriais, associadas à pobreza, carência de rede de apoio sócio-psicológica para a família, ausência da figura paterna e desestruturação familiar. 0 período de institucionalização apresentou-se como doloroso para filhos e genitores. 0 trabalho das instituições envolvidas, 0 desejo dos adolescentes de sair do abrigo e a reestruturação financeira das famílias foram fatores que auxiliaram no desligamento dos abrigados. Contudo, o estudo evidencia a necessidade de um acompanhamento multiprofissional pós-desligamento.

Unitermos: Abrigos. Adolescentes. Desinstitucionalização. Estrutura familiar. Família.
\end{abstract}

\begin{abstract}
This research aimed to evaluate the role exercised by families of adolescents experiencing the process of institutionalization/ deinstitutionalization, in an entity in the city of Uberaba, Minas Gerais. It studied fivefamilies who had regained custody of their children. The materials used to collect the data included semi-structured interviewswith the parent(s), theadolescents themselvesand the director of theinstitution; socioeconomic identification records; examination of theinstitution's record books; adolescents' information files; research field diaries. Theresults showed multifactorial reasons for the sheltering, associated with poverty, lack of socio-psychological family support from the community health centers, absence of the father figure and a poor family structure. The sheltering period was painful for both children and parents. The work of the institutions involved, the adolescents' desire to leavethe institution and the financial restructuring of their families helped with the process of deinstitutionalization. However, the study showed the need for subsequent multi-professional monitoring.
\end{abstract}

Uniterms: Refugies. Adolescents. Deinstitutionalization. Familystructure. Family.

\footnotetext{
${ }^{1}$ Artigo elaborado a partir da dissertação de A.M.G.C.C.V. AZÔR, intitulada "Abrigar... desabrigar: conhecendo o papel das famílias no processo de institucionalização". Programa de Mestrado em Psicologia Aplicada, Instituto de Psicologia, Universidade Federal de Uberlândia. 2005.

2 Universidade Federal de Uberlândia, Instituto de Psicologia. Av. Pará, 1720, 38405-320, Uberlândia, MG, Brasil. Correspondência para/Correspondenceto: C. VECTORE. E-mail: <vectore@ufu.br>.
} 
Compreender e trabalhar com famílias apresenta-se como um dos maiores desafios dos profissionais das mais diversas áreas na contemporaneidade. Nos anos 30, deflagrou-se a inadequação da Instituição da Roda de Expostos ${ }^{3}$ e a necessidade de se investir na família, por meio do reconhecimento do papel fundamental da mãe no desenvolvimento físico, psicológico, social e afetivo da criança (Marcílio, 1998). A despeito da ampla abrangência do conceito "família", um fator que chama atenção é a constatação de que esta, especificamente no Brasil, apesar de estar presente nas políticas getulistas desde os anos 30 , somente no final do século passado (mais precisamente a partir da década de 90) passou a ganhar um maior realce, devido à pluralidade de suas possíveis configurações, à sua indiscutível importância para o desenvolvimento humano e, conseqüentemente, para o desenvolvimento da sociedade. A família é "um espaço indispensável para a garantia da sobrevivência, do desenvolvimento e da proteção integral da criança, independentemente do arranjo familiar" (Fundo das Nações Unidas para a Infância - Unicef, 2005, p.109).

Carvalho (2000), ao discorrer sobre a questão da inserção das famílias nas políticas públicas, aponta uma mudança no que se refere ao papel do Estado no panorama internacional do século passado, que passou do predomínio do WelfareState(Estado do Bem-Estar Social) para a compreensão de que o Estado não supre todas as necessidades do indivíduo. Enquanto no Estado do Bem-Estar Social o desenvolvimento do indivíduo e a sua promoção social se ancoram estritamente na estrutura estatal, nesta outra visão, entende-se que 0 Estado deve compartilhar a missão de sup rir as necessidades do indivíduo com a sociedade civil e a iniciativa privada.

No Brasil, a Constituição Federal (1988), o Estatuto da Criança e do Adolescente (ECA) (Lei Federal n. 8069 de 13 de julho de 1990) e a Lei Orgânica de Assistência Social (1993), além de alguns projetos governamentais, entre eles o Programa de Atenção Integral à Família (PAIF) e o Programa de Saúde da Família (PSF), foram criados com o objetivo de propiciar um atendimento de qualidade às crianças e suas famílias, pelo menos em nível jurídico. Dimenstein (2004) aponta que tais programas sociais freqüentemente apresentam-se fragmentados em suas ações e desconexos nos vários níveis de administração pública, comprometendo os seus objetivos.

Dentro desse contexto, embora o Estatuto da Criança e do Adolescente já tenha mais de quinze anos de existência, é possível constatar situações bastante diferenciadas das previstas pelo documento. A população infanto-juvenil brasileira alcança a cifra de 61 milhões, representando $35,9 \%$ do total da população do país. No que se refere à população adolescente, os dados apontam que $11,6 \%$ são analfabetos e que 14,8\% têm baixa escolaridade, sendo que apenas $10,4 \%$ dos jovens entre 18 e 24 anos encontram-se na faculdade (Instituto de Pesquisa Econômica Aplicada- IPEA, 2003). Tais dados, indiscutivelmente, repercutirão negativamente no futuro desses jovens, que terão muito menos chances de acesso a uma vida digna. $E$, finalmente, 0 recente relatório do Unicef, Situação Mundial da Infância 2007, mostra que o Brasil, emboratenha reduzido a taxa de mortalidade infantil, foi ultrapassado em duas posições no ranking por países com políticas mais eficientes, evidenciando a necessidade de o país melhorar o seu atendimento à infância.

Neder (2000) enfatiza que, ao longo dos séculos da história brasileira, as políticas públicas, quando existiam, eram fortemente influenciadas pelo pensamento vigente, não valorizando as diferenças étnicas e culturais das famílias, principalmente quando as condutas de intervenção tinham como foco a infância ejuventude desvalida, oriundas de estratos menos favorecidos da população. Arantes (1995) e Rizzini (1997) apontam, ainda, a carência de trabalhos efetivos com famílias, sendo curioso observar a escassez de produções científicas acerca da problemática referente à perda do pátrio poder (Alves, 2000) e as conseqüências na vida dos que se encontram institucionalizados. Contudo, deve-se mencionarque, no Brasil, a partir dos anos 80 , iniciativas como a fundação do Centro Regional de Atenção aos MausTratos na Infância (CRAMI), em 1985, no município

\footnotetext{
${ }^{3}$ A Roda de Expostos era um mecanismo giratório, no formato de um cilindro oco de metal ou madeira, com duas portas, uma que se abria para fora e outra para dentro da instituição, fixado normalmente, no muro de locais de acolhimento (hospitais, igrejas), no qual se "depositava" a criança enjeitada em seu 
de Campinas,eda Associação Brasileira Multiprofissional de Proteção à Adolescência (ABRAPIA), fundada em 1988, no Rio de Janeiro, contribuíram para dar visibilidade à questão das crianças vítimas de violência e suas famílias.

No entanto, apesar de uma aparente sensibilização acerca da infância desvalida em várias esferas da sociedade, observa-se que, nessa primeira década do século XXI, as práticas adotadas ainda restringem-se à institucionalização da criança e do adolescente, reforçando a concepção da incapacidade da família em cuidar e, portanto, sublinhando a necessidade de manter 0 afastamento dos filhos, via internação em instituição abrigo. Assim, abrigar a criança ou adolescente apresenta-se

... no Estatuto da Criança e do Adolescente, como medida de proteção (Art. 101, VII) e deve ocorrer quando se verificar uma situação de risco social ou pessoal, definidana lei em razão da: a) ação ou omissão da sociedade ou do Estado; b) por falta, omissão ou abuso dos pais ou responsável e c) em razão da conduta da criança ou do adolescente (Ferreira, 2004, p.2).

Em 2003, foi realizado um Levantamento $\mathrm{Na}$ cional de Abrigos para Crianças e Adolescentes da Rede de Serviço de Ação Continuada, pelo Instituto de Pesquisa Econômica Aplicada. Foram investigados 589 abrigos, sendo que $49,1 \%$ deles estão na Região Sudeste. É interessante constatar que estão em abrigos cerca de vinte mil crianças e adolescentes que, em sua maioria absoluta, têm família (86,7\%), e o motivo mais citado para 0 abrigamento foi a pobreza. Entretanto, apenas $14,1 \%$ dos abrigos desenvolvem trabalhos voltados à reestruturação familiar, como visitas domiciliares, acompanhamento social, reuniões ou grupos de discussão e apoio e encaminhamentos para inserção em programas de auxílio/proteção à família (IPEA, 2003).

Tavares (2001) afirma que as crianças e adolescentes abrigados em instituições tendem a ser população de risco, em virtude, principalmente, da pobreza das famílias de que são oriundos; do afastamento da convivência familiar a que são submetidos; por terem sido vítimas de maus-tratos domésticos; e por não usufruírem de uma rede social de apoio. Além disso, de acordo com Goffman (1987), a própria institucionalização não favorece o desenvolvimento bio-psico-social da criança.
Weber e Kossobdudzki (1996) constataram que a realidade de crianças e adolescentes abrigados é bastante dolorosa, visto que os pais biológicos desaparecem e os jovens ou crianças ficam anos institucionalizados, esperando a família biológica ou adotiva, que dificilmente aparece. Tal situação revela a necessidade de construção de práticas especialmente focadas para as possibilidades de desenvolvimento humano em contextos (Bronfenbrenner, 1996), nos quais se configura o abrigamento temporário, conforme apresentado no Estatuto da Criança e do Adolescente, ou o permanente, levando-se em conta a cristalização do processo de institucionalização que, infelizmente, parece ser 0 destino de um grande contingente de crianças que adentram e vivenciam o cotidiano das instituições voltadas para esse fim.

Vale constatar que, embora os avanços científicos tenham realçado a importância da família para o desenvolvimento humano, em especial os estudos da psicologia relacionados a este tema, eles também revelam a necessidade de se empreenderem esforços no sentido de adequar suas contribuições às práticas institucionais. Winnicott (1999) apontou que osmaus-tratos na infância são muito prejudiciais, acarretando sentimentos de insegurança e atrasos no desenvolvimento. Bowlby (1981) enfatizou que é essencial à saúde mental eao desenvolvimento da personalidade do bebê e da criança pequena a vivência de uma relação calorosa, íntima e contínua com a mãe biológica ou substituta permanente. Todavia, as instituições de abrigo, normalmente com suas práticas prioritariamente disciplinadoras, parecem carecer de uma estrutura capaz de propiciar condições promotoras de um adequado acolhimento. Ao contrário, observa-se a ausência de figuras de referência para a consecução de um vínculo afetivo e efetivo entre aquele que está abrigado e os profissionais atuantes na instituição.

0 objetivo deste estudo foi conhecer o papel desempenhado pelas famílias de adolescentesex-abrigados em uma instituição do município de Uberaba, MG, durante o processo de institucionalização/ desinstitucionalização que viveram. Paratanto, buscou-se identificar os aspectos que contribuíram para a institucionalização; as alterações ocorridas na estrutura familiar, durante o período de abrigamento da criança/adolescente (todos foram abrigados na infância, porém 
saíram do abrigo na adolescência e início da vida adulta); os aspectos que contribuíram para reinserção do adolescente na família biológica; e a situação das famílias após a desinstitucionalização do adolescente.

\section{Método}

\section{Participantes}

0 estudo foi realizado com cinco famílias que tiveram seus filhos abrigados e que recuperaram 0 direito de inseri-los no contexto familiar'. A família 1 constituiu-se da mãe e de seus dois filhos, Antônio e João, abrigados por um período de 14 e de 16 anos, respectivamente. A família 2 constituiu-se da mãe e de seus três filhos, Pedro, Francisco e Adriana, abrigados durante 4 anos. A família 3 constituiu-se do pai e de seus três filhos, Mário e Jennifer, abrigados durante 8 anos, e Marta, abrigada durante 4 anos. A família 4 constituiu-se do pai e de suas duas filhas, Alessandra e Maria, abrigadas durante 11 anos. A família 5 constituiu-se da mãe e de um filho, Alberto, abrigado durante 9 anos. Todas as famílias residiam na cidade Uberaba (MG).

As famílias participantes foram escolhidas de acordo com osseguintes critérios: a) presença de genitor (pai ou mãe) que recuperou o direito à convivência com o(s) filho(s); b) filho(s) institucionalizado(s) por um período igual ou superior a 12 meses; c) desligamento do filho ocorrido há pelo menos 12 meses; d) filho(s) com idade igual ou superior a 12 anos.

O primeiro critério justifica-se pela necessidade de se ter dados oriundos do responsável pela retirada do(a) filho(a) do abrigo, de modo a se conhecer todos os fatores que estão presentes no momento da tomada de decisão pela institucionalização, e também pela desinstitucionalização. Quanto ao tempo de abrigamento, acredita-se que cerca de pelo menos doze meses possibilita um melhor conhecimento da rotina institucional, o mesmo podendo ser dito em relação ao critério de pelo menos doze meses pós-abrigamento, no que se refere às experiências vividas fora do contexto institucional. Em relação à idade igual ou superior a 12 anos, deveu-se à acessibilidade aos instrumentos previstos para a coleta, visto que, com crianças, seria necessária a elaboração de outros materiais para a investigação, o que certamente demandaria um trabalho mais longo, extrapolando o período exigido para a conclusão do estudo.

Instrumentos

Os instrumentos utilizados no trabalho foram: 1) Análise do livro de registros do abrigo, para a seleção da amostra estudada; 2) Fichas de identificação sócio-econômica dos genitores e adolescentes; 3) Entrevistas semi-estruturadas gravadas em áudio com os adolescentes, contendo dados sobre a situação da família no momento da institucionalização (ressalta-se que, por serem bastante jovens no momento do abrigamento, tais dados se referem tanto às suas próprias lembranças quanto a informações transmitidas a eles sobre as experiências durante e após o abrigamento); 4) Entrevistas semi-estruturadas gravadas em áudio com os genitores, contendo dados sobre a situação da família no momento da institucionalização, do período de abrigamento e do período pós abrigamento; 5) Pastas arquivadas dos adolescentes, para a confirmação dos dados oriundos das entrevistas (intercorrências no período de abrigamento); 6) Entrevista com diretora da instituição; 7) Diários de campo.

\section{Procedimentos}

Inicialmente, a pesquisadora, que é funcionária da instituição há mais de uma década, estabeleceu um contato pessoal com a diretora do abrigo, o qual foi devidamente formalizado, de acordo com todos os procedimentos contidos na Resolução n. 196/96 do Conselho Nacional de Saúde (CNS), que trata da pesquisa com humanos, objetivando a permissão para a utilização do livro de registros contendo os nomes de todas as crianças/adolescentes abrigados; as datas de nascimento, de entrada e saída do abrigo; as pessoas responsáveis pelo desligamento, com o grau de parentesco anotado; e os encaminhamentos para outras instituições. Nessa etapa, a pesquisadora selecionou sete famílias. 
A segunda etapa foi definida pela localização das moradias das famílias, que foi realizada, principalmente, pelos endereços obtidos junto ao Programa Bolsa-Escola e pelos funcionários da instituição, que continuam a receber notícias sobre os adolescentes de modo indireto, ou seja, por meio de vizinhos, parentes, outras famílias de abrigados, entre outros. Foi possível contatar cinco famílias (1,2,3,4 e 5), as quais constituíram a amostra estudada.

A terceira etapa foi relativa à aproximação da pesquisadora com as famílias, que foi bastante facilitada pelo fato de ser conhecida por seus membros. Ainda assim, houve resistência por parte dos participantes- pais e/ou mães dos adolescentes, e os próprios adolescentes - observada nos atrasos, no fato de marcar e não comparecer às entrevistas, entre outras ocorrências, que, mostraram que uma pesquisa nesses moldes não é uma tarefa fácil, exigindo constantes reformulações. Esclarece-se que todas as entrevistas foram realizadas nos finais de semana, sendo que, normalmente, uma era feita no sábado e a outra no domingo.

- A família 1 foi procurada inicialmente por telefone, e o contato foi marcado para um domingo, às 15 horas, em sua casa, com o objetivo de fornecer esclarecimentos sobre o trabalho (rapport). A primeira entrevista foi feita com João (ex-abrigado), no sábado seguinte, e teve a duração de aproximadamente 40 minutos. A entrevista com a mãe foi feita na outra semana, e a duração foi de cerca de 50 minutos. A última entrevista foi realizada com Antônio (ex-abrigado), com duração de 55 minutos, perfazendo um total de $2 \mathrm{~h} 25 \mathrm{~min}$ de gravação com a família.

- A família 2 foi procurada pela pesquisadora no local de residência dos participantes, a fim de estabelecerem os dias e horários para a realização das entrevistas. A primeira entrevista foi com Pedro (ex-abrigado), e a duração foi de aproximadamente 35 minutos. A segunda entrevista foi feita com Francisco (ex-abrigado), e a duração foi de aproximadamente 35 minutos. A terceira entrevista foi realizada com a mãe, e durou cerca de 50 minutos. A última entrevista foi realizada com Adriana (ex-abrigada), e durou aproximadamente 40 minutos, perfazendo um total de $2 \mathrm{~h} 40$ min de gravação com a família.

- A família 3, apesar de algumas tentativas fracassadas de contato, foi encontrada em um domingo à noite, quando foram agendadas as entrevistas para o estudo. A primeira entrevista foi realizada com Marta (ex-abrigada), e durou cerca de 40 minutos. A segunda entrevista foi feita com Mário (ex-abrigado), e durou aproximadamente 40 minutos. A terceira entrevista foi realizada com Jennifer (ex-abrigada), em seu local de trabalho, e durou cerca de 50 minutos. A quartae última entrevista foi realizada com J osé (genitor), com duração de cerca de 50 minutos, perfazendo um total de $3 \mathrm{~h}$ de gravação com a família. Todas as entrevistas, com exceção da terceira, foram realizadas na moradia da família.

- A família 4 foi procurada pela pesquisadora no local de residência dos participantes, a fim de estabelecerem os dias e horários para a realização das entrevistas. A primeira entrevista foi realizada com Walter (pai), e teve duração de aproximadamente 45 minutos. 0 segundo encontro foi realizado com Alessandra (ex-abrigada), e durou aproximadamente 40 minutos. 0 terceiro encontro foi com Maria (ex-abrigada), com duração de aproximadamente 45 minutos, perfazendo um total de 2 h10min de gravação com a família.

- A família 5 foi procurada pela pesquisadora no local de trabalho de Joana (mãe), que a recebeu com comportamentos que denotavam hostilidade, como: dirigir-se à pesquisadora de maneira abrupta: Oquevocê quer?; manutenção de pouco contato visual; e atitudes evasivas, minimizando qualquer proximidade físicacom a mesma. Após várias tentativas fracassadas de contato com a mãe, a entrevista foi realizada na moradia desta, e durou cerca de 50 minutos. A entrevista com Alberto (ex-abrigado) teve a duração de cerca de 30 minutos e, ao contrário dos demais adolescentes participantes, foi difícil de ser realizada, devido à baixa motivação deste para participar, o que pôde ser observado porsua recusa verbal inicial em auxiliarno trabalho. As duas entrevistas perfizeram um total de 1h20min de gravação. Esclarece-se que Alberto só concordou em participar devido ao pedido de sua madrinha, em cuja casa a entrevista foi realizada.

Finalmente, foi realizada a entrevista com a diretora do abrigo, que acompanhou a inserção das crianças na instituição e o seu período de abrigamento, visando conhecer e complementar dados referentes a tais aspectos. Após o término da etapa das entrevistas, foram coletados dados oriundos das pastas existentes no abrigo, de modo a se dispor de um material passível de ser confrontado com as informações dos familiares. 


\section{Resultados}

As entrevistas foram transcritas e os dados obtidos foram categorizados e organizados de maneira a permitir a compreensão do processo de inserção de um filho em uma instituição abrigo e de sua retirada para o retorno ao lar, pelo prisma da família. Ascategorias e subcategorias foram elaboradas considerando a experiência da pesquisadora na área e identificadas como: I. Sobreo processo de institucionalização:motivo da institucionalização e reações e sentimentos suscitados por ela; ll. Período de abrigamento: adaptação; experiências significativas do período (facilitadoras e/ ou dificultadoras); visitas; mudanças ocomidas na família durante 0 abrigamento; III. Período de desligamento: fatores desencadeantes do processo de desinstitucionalização; expectativas; dificuldades pós-desligamento; esforços empreendidos; representação da instituição, ou seja, o modo como os participantes se referiam ao abrigo; situação atual da família.

Com o objetivo de clarificar o processo acima aludido, traçou-se um breve perfil referente a cada uma das famílias que o vivenciaram.

- Família 1: Margarida (mãe) nasceu em 19/03/47, é solteira, analfabeta, reside com os dois filhos, João e Antônio, em uma moradia própria, em um bairro de nível socioeconômico baixo. Teve cinco filhos; abrigou dois na instituição pesquisada e três em outra instituição. A renda mensal da família é de $R \$ 350,00$, advinda do trabalho de Antônio, que parou de estudar no primeiro ano do Ensino Médio; João está finalizando o curso de Odontologia. 0 motivo do abrigamento deveu-se ao fato de ter sido abandonada pelo marido e se sentir impossibilitada de cuidar das crianças, por ter que trabalhar. Os sentimentosno momento do abrigamento foram ambíguos, pois, ao mesmo tempo em que o abrigo representavaum local seguro para osfilhos, havia a tristeza pela institucionalização das crianças, conforme sua fala: "Eu senti muita falta, maseu quero vermeusfilhos assim bem estudado... Não tenho vontade de ver eles jogados pelas ruas, mexendo com problema de droga (Margarida)".

Antônio e João referem-se às regras e normas institucionais como dificultadoras do abrigamento, assim como as agressões físicas sofridas no abrigo: "A queera imposto pra gente, porqueelesjá tinham asregras, entre aspas, estabelecidas lá dentro e a gente tinha que adaptar (João)". "Agenteapanhava... Apanhava maisque a geração que está lá hoje(Antônio)".

A mãe visitava quinzenalmente os filhos. Contudo, para Antônio, que foi abrigado com apenas um ano de idade, a mãe era apenas uma mulher que 0 visitava e, somente por volta de dez anos ele compreendeu que aquela pessoa era a sua mãe. Durante 0 abrigamento dos filhos, a mãe trabalhou na roça $e$ adquiriu uma casa. A mobilização para o desabrigamento emergiu do abrigo; Antônio saiu devido a uma briga com agressões físicas e de difícil contenção com outro adolescente abrigado; João queria permanecer no abrigo até o término da Faculdade, mas a direção avaliou que, garantida a continuidade do estudo, não se justificava a prolongação de seu abrigamento. 0 aspecto material foi um dificultador do processo pós-abrigamento. Pelos relatos, a instituição representou uma possibilidade de estudo e oportunidades, conforme se depreende da fala dos jovens e da mãe: "Pelo fato deeu ter sido ajudado, praticamente ajudado, essa também éuma dasminhasmissões, poderterum curso, me ofereço a ajudaralguém... Graçasa Deuseu tô atéhoje e tô bem, tô adorando a Odontologia, tô tranqüilo até agora" ( ( oão). "Lá era grandedemais, espaçoso,tinha lugar para brincar, estudar, essascoisasassim" (Antônio). "Onde ficou eles? É bom né, de ter guardo eles, a satisfação quea gentetinha conversado, satisfação de ter dado educação para eles, aquela grandepaciência com elessabe, dechegar econversar... (Margarida)".

- Família 2: Carmen (mãe), nascida em 26/05/72, concluiu a primeira série do Ensino Fundamental e teve quatro filhos, tendo abrigado três na instituição pesquisada e dado um para adoção; atualmente, trabalha como empregada doméstica. 0 motivo do abrigamento deveu-se aos maus-tratos sofridos pelos filhos, que residiam na casa da avó. $\mathrm{Na}$ época do abrigamento, Carmen morava com outro companheiro, que se recusava a viver junto com seus filhos, eo genitorera ausente, alcoolista, doente e não auxiliava financeiramente. Além disso, a genitora desejava que os filhos tivessem estudo e boa alimentação. Um sentimento comum tanto à mãe, quanto aos seus filhos, foi o medo da adoção: "Tive,tive medo deelesserem adotados, deirpra adoção..." (Carmen). A mãe visitava os filhos regularmente, tendo faltado 
somente duas vezes durante todo 0 abrigamento. Os fatores desencadeantes da desinstitucionalização foram o desejo, as pressões do advogado, os contatos com a instituição judiciária e o esforço da mãe, que trabalhou e adequou-se às exigências materiais. Ela explica: "Fui no advogado... Falou pra mim assim, vocêtá entrea cruze a espada, vocêvai ter queescolher, ou o seu marido, ou os seus filhos, entendeu? A vontade de ter eles comigo... A vontade de ver eles livres... Dinheiro, juntei dinheiro pra comprarosmóveis, ascamasdeles, lençóis, essas coisas, né? Fui trabalhando bastante pra dar conta... Marcando audiência com o juiz, com a psicóloga...Passando por um tipo deteste..." (Carmen).

0 período pós-abrigamento foi marcado por dificuldades de relacionamento dos filhos com o companheiro e problemas financeiros. Para a mãe e os filhos, a instituição representou a possibilidade de estudo e várias aprendizagens: "AAdriana sabecosturar, sabefazer uma comida, sabe arrumar uma casa, entendeu? Aprendeu a mexer em consultório..." (Carmen). "Lá onde vocêia, tinha uma pessoa pra te ajudar, aqui vocênão tem, meu irmão tem que estudar, eu tenho que estudar, aí não dá certo parando e ensinando, lá a "N." me ensinava" (Francisco).

Entretanto, a mãe se ressente por não ter acompanhado os filhos por um perío do longo de suas vidas. Os adolescentes consideram o abrigo fechado, sem possibilidade de participação na comunidade (não poder ir às festas, a existência de horários rígidos etc.). Atualmente, Carmen mora com os filhos Pedro eAdriana e com o companheiro; Francisco mora e trabalha com o pai, não estuda e avalia que sua vida parou pelo fato de desligar-se da instituição, pedindo inclusive à pesquisadora para retornar ao abrigo. A família parece estar se reestruturando adequadamente, com exceção de Francisco, que não se adaptou à estrutura familiar, perguntando inclusive se 0 abrigo 0 aceitaria de volta: "Se eu pudesse voltar para lá, para o abrigo, será que eles aceitariam?". Tal situação pode ser vislumbrada a partir de algumas considerações, como relação insatisfatória com o padrasto e manter amizades com pessoas drogadas. Além disso, Francisco, em suas falas, demonstrou sentir a ausência da disciplina existente no abrigo, principalmente, no que se refere aos estudos.

- Família 3:José (pai) nasceu em 3/5/62, é solteiro, tem o Ensino Fundamental completo. Trabalha em fazenda, ganhando $\mathrm{R} \$ 460,00$ por mês. A família reside em moradia própria; entretanto, somente Jennifer mora com o pai. Na época do abrigamento, os filhos residiam com a mãe (já falecida). Os motivos da institucionalização não são claros, já que as crianças chegaram ao abrigo por meio do Conselho Tutelar; um dos filhos informa que foram abrigados em virtude de José ter abandonado a mãe e esta não ter condições financeiras para sustentá-los. 0 pai soube casualmente do abrigamento dos filhos e, embora tenha ficado chocado, sentiu-se tranqüilo, pois os filhos estavam bem cuidados, tinham boa educação e ele poderia trabalhar sem preocupações. Conforme suas palavras: "Eu não tinha condições de ficar com eles... Eles ficando lá, eu poderia trabalhar mais tranqüilo, sabia que não tinha aquela preocupação de mandar eles pra escola, porque eles estavam sozinhos, né? Então elestava lá, nessa parteaí,ter uma boa educação, eles tavam tendo, coisa que eu não poderia dar, né? Uma boa educação escolar na época" (José).

Contudo, as filhas relatam que as saudades e a dor decorrente da ausência de convivência familiar acompanharam-nas em todo o período de abrigamento. O pai visitava os filhos com freqüência, e a mãe nunca os visitou. 0 desabrigamento ocorreu devido à insistência do judiciário para que J osé retirasse os filhos do abrigo. 0 genitor adequou-se às exigências materiais do judiciário e participou das reuniões com os profissionais do abrigo de maneira freqüente. Explica: "Foi através deacompanhamento depsicóloga, a gentepassou a fazer entrevista, aí o conselho entrou na minha vida, aí foi, explicando algumas coisas, me dando coragem..." (José).

0 período pós-abrigamento foi bastante difícil para todos. Os adolescentes relatam que sentiram saudades do abrigo, devido ao cuidado e à atenção que tinham na instituição, confirmados pelo relato: "Agente acordava com alguém, a tia "l." arrumava a nossa roupa, agora não tem isso mais; tinha gente para dar atenção para a gente..." (Jennifer).

Além disso, os jovens tiveram atritos com o pai. Por outro lado, o pai se queixou da desobediência dos filhos, que culminou com a desestruturação familiar, haja vista a saída dos mesmos para morarem em outros lugares. Ele se arrepende de ter tirado os filhos do abrigo e frustra-se com o fato de não conseguir controlá-los. 
Esclarece: "Eu tinha uma outra expectativa, não esperava que fosse dessa maneira não. Eu esperava que eles fossem meobedecersempre, né?... Eia desconcordarnada comigo, aí então foi a decepção maistarde...Com certeza não tinha trazido eles devolta não"(José).

- Família 4:Walter (pai) nasceu em 12/03/56, tem a segunda série do Ensino Fundamental, teve cinco filhos, sendo que três foram abrigadas na instituição estudada e dois permaneceram com a mãe; é separado e trabalha como zelador, ganhando $\mathrm{R} \$ 330,00$ por mês. De suas três filhas que foram institucionalizadas, a mais nova delas, Cristina, foi adotada. Atualmente, Maria e Alessandra residem com o pai. Na época do abrigamento, os pais estavam separados e a mãe havia abandonado as filhas, que ficavam na rua, pedindo esmolas. As crianças foram encaminhadas à instituição pelo Conselho Tutelare, segundo informações do abrigo, chegaram descuidadas e maltratadas. No que se refere às experiências significativas dentro do abrigo, Walter aponta as agressões físicas sofridas pelas filhas. Ele relata: "Inclusivea Alessandra tem na perna assim, a mordida de um cachorro. Foi D.A. que deixou o cachorro morder a Alessandra... .Como équepode, na creche, no abrigo, um cachorro bravo daqueles lá?" (Walter).

Walter também aponta os maus-tratos morais que sofreu oriundos de profissionais do judiciário. Maria relata que as saudades do pai e a adaptação às regras institucionais foram um dificultador no período de abrigamento. Walter visitava sempre as filhas, e conta que 0 fator desencadeador do desabrigamento foi que parou de beber, insistindo com o juiz na retirada das adolescentes do abrigo. Ele conta: "Fui atémeio carudo, cheguei no juizado. 0 senhorqueéo doutor "L."?Eu queria falar com o senhor um momentinho.... É sobre o quê? As meninas estão lá no abrigo... Ele falou: se o senhor quiser quelibereas meninasé só falar, queeu mando uma carta para o abrigo. Eu pedi pra elemedardoismeses deprazo... Quando foi em agosto, tirei elas de lá... . No final a pessoa tem queabandonar,enquanto eu bebesseelenão ia liberar. Seeu parasse, ele liberaria..." (Walter).

O período pós-desligamento foi e continua sendo difícil para o pai e as filhas, devido tanto às dificuldades de relacionamento entre eles, quanto aos problemas econômicos. Todos acreditam que 0 abrigo proporcionou aprendizagem e oportunidades. Maria queestude, que saiam delá formados equetenham a sua casa. Tudo isso. Aproveitar enquanto estão lá (sic)".

- Família 5: Joana (mãe) nasceu em 18/09/74, concluiu a terceira série do Ensino Fundamental, é solteira, mora com o filho e trabalha como faxineira, obtendo uma renda mensal de $R \$ 320,00$. Seu filho Alberto nasceu em 05/08/91, cursa a quinta série e não gosta de estudar. Os motivos do abrigamento foram a inexistência de um lugar adequado para morar, falta de apoio familiar, dificuldade de encontrar trabalho com um filho pequeno, e por ser muito nova (15 anos). A mãe relata que, inicialmente, apresentou indiferença em relação ao abrigamento de seu filho, eque desejava tê-lo deixado mais tempo na instituição, visando protegê-lo das drogas e estruturar melhor a sua vida financeira. Ela relembra: "Eu era tão criança que eu não ligava pra nada não, pra mim estava tudo bem. Sabe, a gente não pensa... Pensava em arrumar minha casa própria primeiro, esperava e pensava nele crescer lá, mas não deu certo, tive quetirar ele de lá... As coisas que eu tenho medo aqui fora agora, lá dentro eu tenho certeza que não teria. Por que podeseenvolvercom drogas, com pessoasquepodepassar coisas ruins pra ele, disso que eu tenho medo" (Joana).

0 período de abrigamento possibilitou à mãe trabalhar. Quanto ao adolescente, percebe-se que 0 abrigamento Ihe trouxe algumas experiências agradáveis, referindo-se somente aos colegas, às visitas e às brincadeiras como algo gratificante e ressaltando o fato de sentir-se preso, de apanhar e de dormir muito cedo, como experiências ruins. A mãe sempre visitou o filho, que aproveitava para pedir-lhe a saída do abrigo. 0 pós-desligamento tem sido uma experiência difícil para mãe e filho,em virtude do não entrosamento entre eles. 0 adolescente passa 0 maior tempo na casa de uma vizinha e na rua, não fazendo referência à mãe ou à própria casa. A mãe considera que deveria ter tido uma preparação psicológica e não somente ajuda financeira. É interessante observar que tal suporte psicológico foi oferecido por estagiários do curso de Psicologia, sendo recusado por ela. Por meio dos relatos da mãe e de seu filho, compreende-se que a institucionalização parece ter sido algo doloroso e que o abrigamento, por um perío do de nove anos, foi prolongado demais, gerando um grande distanciamento entre mãe e filho, e uma aparente ausência de vínculo entre eles. Ela menciona: 
"Eu não teria deixadoelelá noveanos.Porquecoma cabeça queeu tenho hoje,ecom o apoio queeu tenho,eu não teria deixado ele lá dia nenhum, nem um ano" ( 0 oana).

\section{Discussão}

Compreender o processo de institucionalização/ desinstitucionalização sob a ótica das famílias, da instituição abrigo e dos próprios abrigados, foi o objetivo perseguido por este estudo que, apesar de suas modestas proporções, parece lançar alguma luz no intrincado quebra-cabeça que constitui tão controversa realidade.

Como ocorre o processo de institucionalização da criança? Preliminarmente, chama a atenção que tal processo caracteriza-se como uma somatória de um grande número de variáveis, que podem ser identificadas desde o pertencimento das famílias aos estratos mais inferiores da sociedade, até fatores de adoecimento psíquico (alcoolismo e drogas, por exemplo, observados nas famílias 3 e4) que, em algum momento da trajetória das famílias, se inter-relacionam e desestruturam a frágil organização familiar, culminando com uma medida extrema, representada pelo afastamento do membro mais suscetível, ou seja, a criança pequena.

Nas cinco famílias estudadas, observa-se que 0 baixo nível socioeconômico foi predominante na deflagração do processo de institucionalização, gerado pela falta de moradia, trabalho, entre outros fatores. Outros estudos corroboram o resultado acima mencionado, como os de Weber e Kossobdudzki (1996), Alves (2000)e os dados da pesquisa coordenada por Silva (2004).

Todavia, o aspecto socioeconômico não aparece isolado em nenhuma família, mas reforçado com outros indicadores: maus-tratos, maternidade precoce, comprometimento psíquico, história de vida dos genitores e número elevado de filhos, conforme pode ser comprovado pelo perfil apresentado das famílias. Segundo Sawaia (2002), a população, quando submetida a situações adversas por longo período, desenvolve um sentimento contínuo de desamparo e desesperança.

Outro fator predominante nas cinco famílias estudadas diz respeito à ausência da figura paterna. De fato, dos cinco genitores do sexo masculino, quatro estavam ausentes e não participaram do processo de abrigamento dos filhos, porterem abandonado a família e, dentre as possíveis implicações desse abandono, ressaltam-se a falta de respaldo financeiro e a ausência de apoio psicológico, necessários para a criação dos filhos.

Em relação à questão dos maus-tratos ou violência, Azevedo e Guerra (2000) apontam que existem dois processos fundamentais que resultam no aparecimento das crianças-vítimas. São eles: o processo de vitimação, gerador de "crianças de alto risco", isto é, vítimas da violência estrutural característica da sociedade brasileira, perversamente desigual na distribuição de riquezas, permitindo a contínua violação dos seus direitos, como o direito à vida, saúde, alimentação, educação. 0 segundo processo, denominado de vitimização, desencadeia 0 aparecimento das "crianças em estado de sítio" e implica, necessariamente, em abuso físico ou psicológico à criança.

A maternidade precoce foi identificada em duas famílias como um indicador para a institucionalização da criança, e não se apresenta como um fato isolado, pois, de acordo com Oliveira e Flores (1998), a negligência aparece com maior freqüência em mães de pouca idade, aumentando significativamente quando necessitam criar os filhos sozinhas. Vale apontar que, no estudo em questão, tal fator não foi identificado.

Em relação às reações e sentimentos dos genitores, no momento do abrigamento dos filhos, foi possível constatar, por meio de seus relatos, a vivência de uma experiência extremamente sofrida e difícil. Não obstante uma das mães participantes ter relatado indiferença, todos os demais sentiram medo de que os filhos fossem adotados, além de tristeza e revolta por terem que se afastar deles.

Segundo Weber e Kossobdudzki (1996) é prática comum, após um longo processo de abrigamento, o afastamento dos pais em relação aos filhos. Todavia, neste estudo, os cinco genitores, rep resentados por três mães e dois pais, empreenderam esforços para que tal afastamento não se concretizasse, e a instituição foi concebida como a única opção para garantir um atendimento de melhor qualidade para os filhos.

Por meio do relato das mães e pais participantes e das fichas de identificação, é possível observar a 
presença de três aspectos considerados facilitadores no período relativo ao abrigamento dos filhos. São eles: a) possibilidade de reestruturação econômica da família; b) possibilidade de auxílio dos profissionais vinculados às instituições abrigo, Judiciário e Conselho Tutelar, o que, infelizmente, parece depender da sensibilidade dos profissionais envolvidos, pois não se trata de uma conduta institucionalizada de efetivo apoio às famílias; $\mathrm{e} \mathrm{c}$ ) possibilidade de acesso à educação formal ou informal para os filhos, propiciada pela instituição.

0 que pensam hoje os que efetivamente passaram pelo processo de institucionalização/desinstitucionalização, sobre esse período de suas vidas? De acordo com os dados coletados, os atuais adolescentes ejovens consideraram que a adaptação foi uma experiência particularmente difícil, devido principalmente à existência de agressões físicas, à rigidez das regras institucionais, à ausência e saudade da família e, especialmente, ao momento de dormir, em que é freqüente o sentimento de medo. Guirado (1986) e Altoé (1993) mencionam que a agressão física é uma prática primitiva disciplinadora e freqüente no contexto institucional.

As regras, as normas e mudanças institucionais, além da ausência de liberdade e da família, deflagram a impossibilidade de se preservar no abrigo um "eu" desejoso e pensante. Assim, o singular dá lugar ao coletivo, por intermédio de uma transformação desencadeada por hierarquias e autoridades. 0 despojamento da identidade insere-se na caracterização de "instituição total", elucidada por Goffman (1987), ao comentar a "mortificação do eu" - pois os indivíduos, ao serem abrigados, passam por um processo de "mutilação" de sua identidade, que se inicia com a barreira colocada entre abrigados e mundo externo, seguindo-se com o processo de admissão que implica, entre outras medidas, em guardar os objetos pessoais, cortar os cabelos, vestir roupas da instituição e receber instruções quanto às regras; e, finalmente, com a imposição de uma rotina de vida estranha à sua singularidade. Para Bowlby (1981), a constituição de tal panorama opõe-se à possibilidade de um desenvolvimento saudável na infância e juventude. As mudanças típicas da adolescência parecem dificultar o abrigamento. Segundo Winnicott (1999), há necessidade de se ter um "ambiente facilitador", com a assim, manter os dados da realidade. Esses mesmos fatores, presentes na situação de institucionalização, podem explicaro desejo de voltar/permanecer no abrigo, expresso por alguns dos adolescentes pesquisados.

A relação com as cuidadoras é apontada como uma experiência facilitadora por alguns adolescentes, devido ao contato mantido com os abrigados. É freqüente tornarem-se figuras de referência, quer seja de modo adequado ou inadequado. Em relação às visitas, depreende-se que se tratava de um momento prazeroso, no qual se tinha notícias "lá de fora" e era possível expressar o desejo de sair do abrigo, mobilizando os pais na busca de alternativas para retirada da instituição.

No que se refere às mudanças ocorridas na família, no perío do de abrigamento, constata-se que a reestruturação financeira foi comum a todas elas, e o "divisor de águas" que viabilizou o desabrigamento. Entretanto, 0 desejo ter os filhos de volta ao lar parece ter sido a mola propulsora de tal iniciativa.

Qual ou quais os sentimentos das famílias, após os anos de abrigamento dos filhos? Quanto a essa questão é interessante observar o relato de Carmen, da família 2, demonstrando arrependimento pela internação dos filhos: "Perdi as melhores partes do crescimento dosmeusfilhos, aproveitei muito pouco... Hojeeu não faria isso denovo, hojeeu ia pra debaixo da pontecom eles, mas não faria isso. Não dou eles pra sicrano nem para fulano" (Carmen).

Os adolescentes participantes deste estudo apresentam indicadores de risco, conforme os apontados por Antoni e Koller (2000), levando ao questionamento: por que alguns, diante de um mesmo contexto, apresentam vulnerabilidade e outros não? Uma das respostas pode ser a constatação de que a existência do indicador de risco não implica necessariamente vulnerabilidade, pois há aspectos inerentes à resiliência individual que protegem 0 indivíduo de desencadear um distúrbio perante um fator de risco, conforme demonstrou J oão, que conseguiu concluir o curso de Odontologia. Por resiliência, entende-se a busca "...de compreender os processos e condições que possibilitam a "superação" de situações de crises e adversidades" (Yunes, 2003, p. 83).

É interessante apontar as iniciativas internacionais mencionadas por Tolan e Dodge (2005) e Huang 
et al. (2005), que enfatizam o papel do treinamento, da pesquisa e da prática de intervenções psicológicas na organização de políticas públicas visando a promoção da saúde mental em crianças e famílias em situação de risco, por meio do oferecimento de serviços culturalmente competentes para as mesmas.

A partir do estudo ora apresentado e das tendências observadas na literatura pertinente, algumas sugestões podem ser oferecidas, de modo a favorecer um abrigamento com mais qualidade. Ei-las:

1) A recep ção da criança/adolescente no abrigo deve ser acolhedora e educada, incluindo a apresentação do espaço físico, das normas, das rotinas institucionais e das pessoas. Paulatinamente, no decorrer dos dias, é importante esclarecer-lhe os motivos do abrigamento e, a priori, enfatizar que o abrigo é uma condição provisória, sem atribuir à família qualquer conotação negativa, respeitando o tempo da criança para falar sobre 0 assunto.

2) A hora de dormir, principalmente para as crianças pequenas abrigadas, apresenta-se difícil e dolorosa, por desencadear saudades da família, medo e solidão. Assim, é desejável a presença de um adulto em condições de compreender esse momento e de assumir uma referência segura e firme, por meio de conversas sobre as atividades do dia, orações, histórias, entre outros.

3) 0 momento das visitas da família apresenta-se como um dos melhores momentos do período de abrigamento das crianças/adolescentes. Sugere-se que essas ocorram com uma freqüência semanal, no mínimo, e que sejam acompanhadas por profissionais, atentos à interação família/criança, com posteriores intervenções com os genitores, sempre que necessário.

4) A relação abrigo/família apresenta-se como um dos maiores desafios da instituição, ea possibilidade de 0 abrigo contribuir com o desenvolvimento da criança/adolescente implica, necessariamente, no reconhecimento de que não pode substituir a família e, por tal razão, deve investir no trabalho com ela, visando ao desabrigamento rápido, sempre que possível.

5) 0 abrigo pode e deve favorecer 0 desenvolvimento da infância e juventude à medida que propicia, além da educação formal, espaços visando à preservação dos vínculos de irmandade e atendimentos individualizados não psicoterapêuticos, objetivando oferecer à criança/adolescente uma escuta individualizada, que favoreça a possibilidade de preservar o "eu" dentro de uma estrutura coletiva com tendência a oprimi-lo (Goffman, 1987). Os atendimentos psicoterapêuticos podem apresentar-se de grande valia para a infância/juventude abrigada, entretanto, devem ser realizados na comunidade, com profissionais não ligados ao abrigo.

6) A capacitação contínua dos funcionários é imprescindível para viabilizar qualquer projeto institucional. Assim, alternativas como a técnica de Grupos Operativos de Pichon-Riviére (2000), e/ou a utilização de estratégias de mediação em contextos de abrigo, conforme sugere Vectore (2005), podem ser adequadas para esse perfil de atendimento.

\section{Considerações Finais}

Na sua totalidade, as famílias estudadas tinham as melhores expectativas quanto ao desabrigamento dos filhos, embora os motivos fossem diferentes. Vale mencionar que, mesmo na família 5 , na qual se observa certa pressão do judiciário e um desejo, por parte do menino, de sair da instituição, havia a esperança de poder ter uma convivência harmônica entre mãe e filho, conforme as palavras da mãe: "Esperava uma convivência diferente, mãeefilho amigos, companheiros; não esperava essa coisa doida não" (Joana).

Todavia, o período após o desabrigamento apresentou-se repleto de dificuldades, principalmente devido às questões de ordem material (falta de conforto das moradias, despesas com alimentação, entre outras).

Sofrer a experiência de abrigamento constituiu-se como paradoxal para a grande maioria dos adolescentes entrevistados. Pormeio de seus relatos,é possível compreender que 0 abrigo, seja em função de outros colegas abrigados, dos funcionários, da oportunidade de estudo, ou do longo período de abrigamento, favorece o estabelecimento de um vínculo afetivo, representando a família, o que pode explicaradificuldade de alguns para se desligarem da instituição. Entretanto, os adolescentes também apontam aspectos negativos do abrigo, como a ausência de liberdade, a presença de castigos e regras, o isolamento e a sensação de prisão 
que os envolvem; em conseqüência, a comunidade apresenta-se distante, 0 "lado de fora",e a família parece representar o elo de conexão desses dois contextos sociais.

Finalmente, conseguir retirar o filho de uma situação de institucionalização e trazê-lo de volta à família é, na verdade, um indicador de uma efetiva reestruturação familiar? Embora o presente trabalho não tenha o objetivo de responder a essa questão, os dados obtidos permitem constatar que a questão do abrigamento das crianças/adolescentes é multifatorial, conforme já mencionado. Desse modo, a reestruturação familiar é apenas um elo dessa grande corrente, sendo necessárias outras medidas que garantam a permanência na família.

Assim, há necessidade de políticas públicas eficazes, quer seja em nível federal, estadual ou municipal, atreladas à intervenção de uma equipe multiprofissional, maximizando e otimizando 0 atendimento, resgatando a auto-estima das famílias e pautando-se na compreensão reflexiva das causas e no reconhecimento dos recursos de natureza externa e interna de que dispõe a família, não se fixando apenas no aspecto financeiro, mas também compreendendo o peso de variáveis afetivas e sociais, na tão almejada reconstrução familiar.

Desse modo, o desabrigamento de crianças e adolescentes não é o final de um processo de desestruturação/reestruturação familiar biológica, mas apenas uma etapa do processo, que demanda acompanhamento pós-abrigamento sistemático e bastante criterioso.

Uma palavra final pode ser dada ao apontarque os participantes desse estudo, em sua maioria, foram institucionalizados antes dos seis anos de idade. Considerando-se a importância do período de zero a seis anos de vida para um adequado desenvolvimento humano, sugere-se que estudos maciços devam ser continuamente empreendidos, no sentido de oferecer a prestação de um serviço de qualidade, tanto a essas crianças, quanto às suas famílias. Para tanto, há a necessidade da compreensão do fenômeno em toda a sua extensão e sutilezas, bem como de fomentar, em última instância, um espaço de saúde mental, capaz de contribuir com a construção de um ser humano mais solidário e participante no seu contexto social.

\section{Referências}

Altoé, S. (1993). Demenor a presidiário: a trajetória inevitável. Rio de Janeiro: Universitária Santa Úrsula.

Alves, E. S. (2000).Abrigamento decriançaserealidadefamiliar. A desmistificação do abandono. Dissertação de mestrado não-publicada, Universidade Federal de Santa Catarina, Florianópolis.

Antoni, C. \& Koller, S. H. (2000). Vulnerabilidade e resiliência familiar: um estudo com adolescentes que sofreram maus tratos intrafamiliares. Psico, 31 (1), 39-66.

Arantes, E. M. M. (1995). Rostos de crianças no Brasil. In F. Pilotti \& I. Rizzini (Orgs.), A arte de govemar crianças (pp.172-220). Rio de Janeiro: Universitária Santa Úrsula.

Azevedo, M. A., \& Guerra, V. N. A. (2000). Vitimação e vitimização: questões conceituais. In M. A. Azevedo (Org.), Crianças vitimizadas:a sínd romedo pequeno poder(2a.ed.). São Paulo: IGLU.

Bowlby, J. (1981). Cuidados maternos e saúde mental. São Paulo: Martins Fontes.

Bronfenbrenner, U. (1996). A ecologia do desenvolvimento humano. Porto Alegre: Artes Médicas.

Carvalho, M. C. B. (2000) (Org.). A família contemporânea em debate (3a.ed.) São Paulo: Cortez.

Dimenstein, G. (2004). Lula tem o corpo do Brasil. Folha de São Paulo, Caderno C, São Paulo.

Ferreira, L. A. M. (2004). O promotor de justiça frente à institucionalização de criança e adolescente em entidade abrigo e a destituição do poder familiar. Recuperado em dezembro 22,2005, disponível em http://www.pjpp.sp. gov.br

Fundo das Nações Unidas para a Infância. (2006). Relatório da situação mundial da infância 2007. Recuperado em março 11, 2007, disponível em http://www.unicef. org.brl

Goffman, E. (1987).Manicômios, prisõeseconventos. São Paulo: Perspectiva.

Guirado, M. (1986). Instituição e relações afetivas: 0 vínculo com o abandono. São Paulo: Summus.

Huang, L., Stroul, B., Friedman, R., Mrazek, P., Friesen, B., \& Pires, S. (2005). Transforming mental health care for children and families. American Psychologist, 60 (6), 615-627.

Instituto de Pesquisa Econômica Aplicada. (2003). Levantamento nacional deabrigos para crianças eadolescentes da Rede deServiço deAção Continuada. Brasília: Autor.

Lei Orgânica de Assistência Social. (1993). Lei no 8.745, de 7 de dezembro de 1993.

Marcílio, M. L. (1998).A história social da criança abandonada. São Paulo: Hucitec.

Neder, G. (2000). Ajustando o foco das lentes: um novo olhar sobre a organização das famílias no Brasil. In S. Kaloustian (Org.), Família brasileira a base detudo (4a.ed., pp.26-46). São Paulo: Cortez.

Oliveira, M., \& Flores, R. (1999). Violência contra crianças e adolescentes na Grande Porto Alegre. In Associação do 
Menor Carente (Org.), Violência doméstica (pp.104-117). Brasília: Unicef.

Pichon-Riviére, E. (2000). O processo grupal (6a.ed.). São Paulo: Martins Fontes.

Rizzini, I. (1997). O século perdido.Rio de Janeiro:Universitária Santa Úrsula.

Sawaia, B. (2002) (Org.). As artimanhas da exclusão: análise psicossocial e ética da desigualdade social (4a.ed). Petrópolis: Vozes.

Silva, E. R. A. (2004) (Coord.). O Direito à convivência familiare comunitária:osabrigospara criançaseadolescentesno Brasil. Brasília: IPEA.

Tavares, J. (2001). Resiliência eeducação (2a.ed.). São Paulo: Cortez.

Tolan, P. H., \& Dodge, K. A. (2005). Children's mental health as a primarycare and concem:a system for comprehensive support and service. American Psychologist, 60 (6), 601-614.

Vectore, C. (2005). Estratégias mediacionais. In A.M. Martinez (Org.), Psicologia escolar:compromisso social (pp.155-175). Campinas: Alínea.

Weber, L. N., \& Kossobdudzki, L. H. (1996). Filhos da solidão. Curitiba: Governo do Estado do Paraná.

Winnicott, D. W. (1999). Tudo começa em casa (3a. ed.). São Paulo: Martins Fontes.

Yunes, M. A. M. (2003). Psicologia positiva e resiliência: 0 foco no indivíduo e na família. Psicologia em Estudo, 8 (Número especial), 75-84.

Recebido em: 6/1/2006

Versão final reapresentada em: 29/5/2007

Aprovado em: 10/9/2007 
